\title{
Is Covid-19 Sibling of SARS AND MERS? A Review on: Novel Covid-19
}

\author{
Savita Devi', Kamaldeep Singh ${ }^{2, *}$ \\ ${ }^{1}$ Department of Medical Laboratory Technology, School of Paramedical and Physiotherapy, Lovely Professional University, \\ Punjab, INDIA. \\ ${ }^{2}$ Department of Medical Lab Technology, School of Medical and Allied Sciences, Galgotias University, Greater Noida, \\ Uttar Pradesh, INDIA.
}

\begin{abstract}
Pandemic times: Contemporary public health catastrophe terrifying the world over with the rapidly spreading of $2019-\mathrm{nCoV}$ or SARS-CoV-2. Coronaviruses have pass over the species barriers to cause fatal disease in human since the 2002 and 2012; Severe Acute Respiratory Syndrome and Middle East Respiratory Syndrome respectively. It was suggested that SARS-CoV and SARS-CoV-2 are firmly related to each and hypothesized it originated in animal (bats) and was transmitted to humans. Though Novel Covid-19's intermediary animal is not clear. As a matter of fact, transmission of Covid-19 is direct contact with infected people or inhalation of droplets thus; escalate its spread. World Health Organization stated the novel SARS-CoV-2 is one of the epidemic disease on January 30, 2020 and on March 11, 2020 declared a pandemic the rapidly spreading SARS-CoV-2- a globe first for corona virus. Additionally, the incubation phase is from 2 to 14 days. Usually the sign and symptoms are high temperature, dry cough, tiredness, sore throat, difficulty breathing (severe cases) AND malaise among others. The diagnosis can be done with Real Time Polymerase Chain Reaction test to suspected SARS-CoV-2 infection along with chest X-ray. Till time, no medicine or vaccines are prepared that can approved against SARS-CoV-2 or any human-infecting corona viruses. But some researchers have confirmed to curtail its effects by administrating antiviral drugs such as Oseltamivir, Ribavirin, Ganciclovir, Lopinavir AND Ritonavir.
\end{abstract}

Key words: SARS-CoV-2, Corona virus, Epidemic, Pandemic, PCR.

\section{INTRODUCTION}

Coronavirus (CoVs) which belongs to the coronavirus family containing biggest genome of all well-known RNA viruses. It is generally found in humans, dogs, mice, pigs, cats AND other species of animals. There are total VII species of coronavirus and IV species namely- HCoV-NL63, HCoV229E, HCoV-OC43 and HCoV-HKU1 among seven which are known to provoke human disease; especially, cause respiratory infections in infants, immune compromised individual AND the elderly. Three species SARS-CoV, SARS-CoV-2 and MERS-CoV and SARS-CoV-2 are highly pathogenic human coronaviruses among other species, which cause the severe acute respiratory syndrome and the Middle East respiratory syndrome (SARS- CoV), (MERS-CoV) respectively. Coronaviruses are known to cause multiple organ failure (MOF), hepatic, intestinal, respiratory and neuronal diseases and may lead to cause acute respiratory distress syndrome (ARDS) AND even death may occur in severe cases. ${ }^{1-4}$ Over the previous decades, two viruses, SARS-CoV and MERS-CoV, have appeared and create and cause severe illness or disorders in humans. ${ }^{5,6}$ During the epidemic of SARS$\mathrm{CoV}, 8000$ people the world over infected, with near about eight hundred and more are fatalities, delineating its was also observed that mortality rate of this infection was
Submission Date: 01-04-2020; Revision Date: 09-05-2020; Accepted Date: 17-06-2020

DOI: 10.5530/ijper.54.3.97 Correspondence: Mr. Kamaldeep Singh Department of Medical Lab Technology, School of Medical and Allied Sciences, Galgotias University, Greater Noida-201310, Uttar Pradesh, INDIA.

Phone: +919910428021

E-mail: kamaldeepbilkhu53@ gmail.com

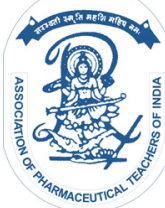

www.ijper.org 
around 10\%. While MERS-CoV the second virus infected more than eight hundred and fifty seven people all over the world and number of pupil died during this period was three hundred and thirty four, observed the mortality rate near to or approximately $35 \% .{ }^{7,8}$ According to World Health Organisation there have been around 38,55,788 cases reported across the globe of COVID-2019 including 190+ countries and 2,65,849 reported deaths by May 09, 2020, representing its mortality $6-7 \%$.

[https://www.who.int/docs/default-source/ coronaviruse/situation-reports/20200509 covid-19sitrep-110.pdf?sfvrsn=3b92992c_4].

As a matter of fact, SARS-CoV-2 (Severe Acute Respiratory Syndrome Coronavirus 2) is a recently recognize novel type of coronavirus of $\beta$ genus which is leading to develop infectious disease with impressive pulmonary involvement in China since December 2019. Having said that, it belongs to the coronavirus family which includes the similar clinical features of other species but specifically; high temperature, dry cough, breathing shortness, leucocytosis or normal peripheral WBCs AND inflammatory changes can be seen mainly on chest X-ray. SARSCoV- 2 has been designated infected pneumonia as a statutory infectious disease by
China. 'The diagnosis of SARS Cov-2 can be done with the help of Real Time Polymerase Chain Reaction test along with chest X-ray and other screening criteria as mention in Figure 1. ${ }^{10}$

\section{CORONA VIRUSES STRUCTURE}

Furthermore, CoVs exist to the subcategory namelyCoronavirinae, in the breed it belongs with Coronaviridae of the order to effect humans and animals both called as Nidovirales. Coronaviruses are single- that mean comes under a single RNA and +ssRNA viruses. The genomic structure show a colossal genome nearby $30 \mathrm{~kb}$ in length which is considered largest genome of all known RNA viruses. ${ }^{11}$ further this genome consist two encoded protein named- first SPs (mean structural proteins) and second NSPs (mean Non-structural proteins). Additionally, special structural and accessory proteins are also encode by some of the CoVs. All well known RNA CoVs share a akin structure which are specifically made of four main structural proteins -namely; spike $(\mathrm{S})$, nucleocapsid $(\mathrm{N})$, envelope (E) AND membrane (M) proteins. ${ }^{12}$ The prominence of the components are such as S-protein which mainly helps for the binding to host receptors, while $\mathrm{M}$ proteins responsible for the

\section{Diagnosis of SARS Cov-2}

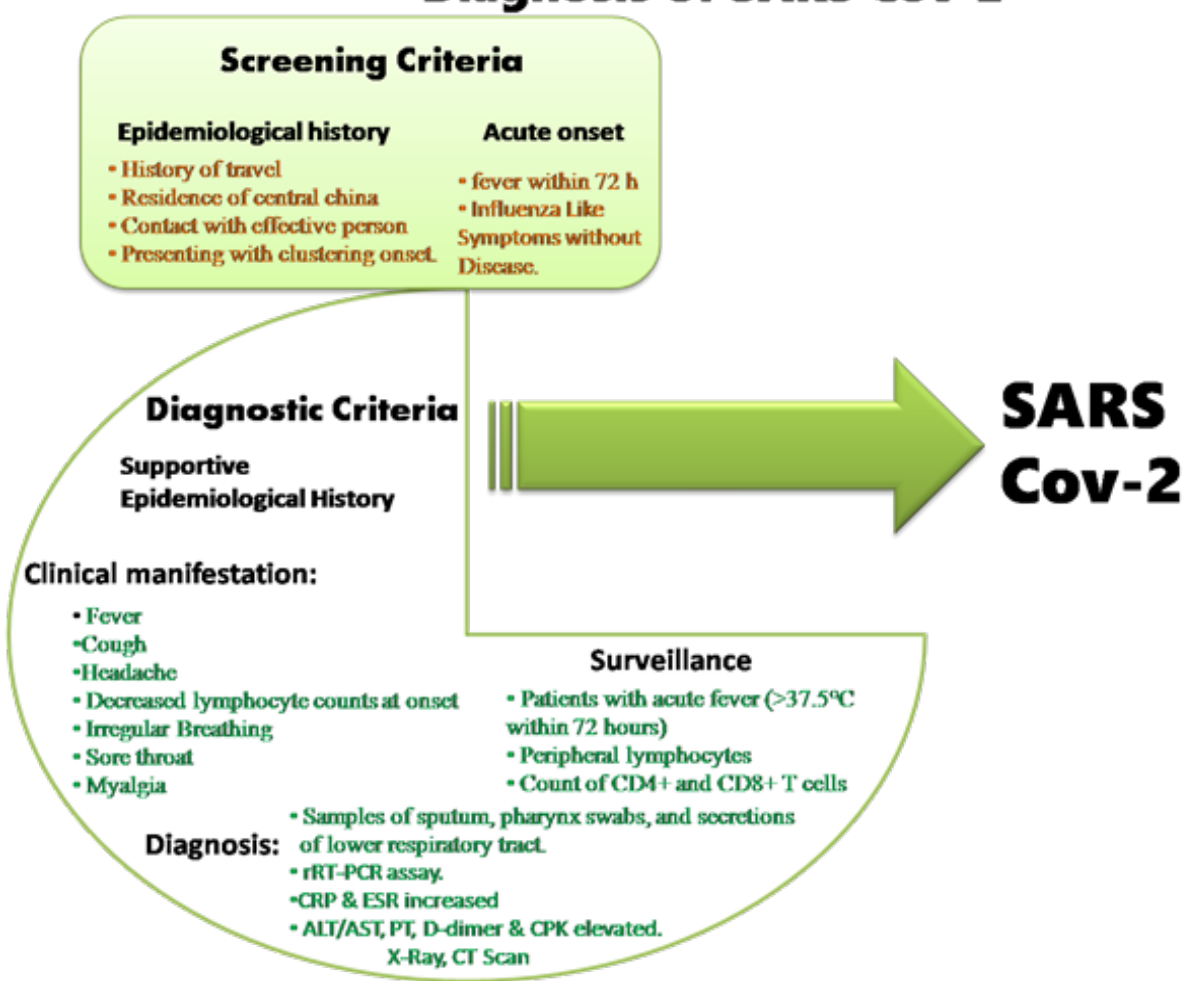

Figure 1: This figure depict that different types of approach take place for diagnosis of SARS cov-2. Major feature of diagram is SARS Cov-2 can be diagnosed with rRT-PCR assay with the help of other screening criteria. 
development of entire shape which contain outer shell as capsid and inner core as nucleic acid. Envelope protein plays a pivotal aspect in the aggregation and discharge of particles whilst $\mathrm{N}$-protein mainly helps in the replication process, especially in replication-transcription complex by the binding of the genome. ${ }^{13}$ The spikes of SARS$\mathrm{CoV}$ are made up glycoprotein that are disclose on the envelope of the virus surface and construct spikes from the virus body. This is constitute 1255 long amino acids, with 20-27 per cent amino acid similarity among other type of coronaviruses but its C-terminus (carboxyl terminus) is made up of the trans membrane region and from the cytoplasmic tail. ${ }^{14}$ Whereas, its extracellular domain's spike glycoprotein is comprised of two heptad repeat regions which namely as-HR1 (heptad repeat region 1) and HR2 (heptad repeat region 2$)^{15}$ But in case MERS-CoV spike proteins made up 1353 amino acids. It has a type I trans membrane glycoprotein and heavily glycosylated. Moreover, have a huge extracellular domain and a short shape and size cytoplasmic terminal. Furthermore, there are two subunits S1 and S2 subunit $\mathrm{S} 1$ has an N-terminal domain has comprises 240 residues and a receptor-binding domain. Similarly, SARS-CoV it has two regions in the S2 subunit namely as similar previous one, HR1 and HR2, which participate in viral fusion. ${ }^{16}$ Finally, the structure of novel SARS-CoV-2 which also belongs to the beta $\mathrm{CoVs}$ category. Its genome consist 29891 nucleotides in structure, encoding for 9860 amino acids. S protein of SARS-CoV-2 generally made up for glycosylation process with the help of $22 \mathrm{~N}$-linked sequuons/ protomer. Similarly, the oligosaccharides compounds are deal with in the cryoelectron microscopy map for 16 sites. Whereas SARS$\mathrm{CoV} \mathrm{S}$ on other hand possesses the same glycosylation process with the aid of $23 \mathrm{~N}$ - linked sequins/ protomer. However, its origins are not absolutely understood; investigation suggest that CoVid-19 probably emerge from a strain found in bats. ${ }^{17}$

\section{PATHOGENECITY}

As compare with previous coronaviruses so far, the new COVID-19 (SARS-CoV-2) has been more infectious as per given data of WHO but this novel virus killing speed is less. (Table 1).

SARS-CoV-2 is a novel coronavirus. Firstly it was pinpoint on 8 December, in city Wuhan, China. ${ }^{17,18}$ SARS-CoV-2 is entering as a new participant of coronaviruses' family. Coronaviruses generally noted comes are a single-stranded RNA largely group of highly distinct virsuses. Majorly its has outer cover envelope and positive-sense characteristics. ${ }^{18}$ Recently,

\begin{tabular}{|c|c|c|c|c|}
\hline \multicolumn{5}{|c|}{ Table 1: Data comparison of SARS-CoV, MERS-CoV } \\
\& SARS-CoV-2 \\
$\begin{array}{c}\text { Type of } \\
\text { Virus }\end{array}$ & $\begin{array}{c}\text { Recognition } \\
\text { Year }\end{array}$ & $\begin{array}{c}\text { Number } \\
\text { of cases } \\
\text { present } \\
\text { in } \\
\text { Humans }\end{array}$ & $\begin{array}{c}\text { Numbers } \\
\text { of fatal } \\
\text { humans }\end{array}$ & $\begin{array}{c}\text { Death } \\
\text { ratio } \\
\text { (\%) }\end{array}$ \\
\hline SARS-CoV & 2002 & 8,096 & 744 & $9.19 \%$ \\
\hline MERS-CoV & 2012 & 2,494 & 858 & $34.04 \%$ \\
\hline $\begin{array}{c}\text { SARS- } \\
\text { Cov-2 } \\
\text { (Noval } \\
\text { Covid-19) }\end{array}$ & 2019 & $38,55,788$ & $2,65,862$ & $6-7 \%$ \\
\hline
\end{tabular}

researchers have reported that bats are the common likely responsible to origin of SARS-CoV-2, but not sure. Since, based on the other features and similarity of genome, its sequence and nature of materials to that of other types of corona viruses already has such as SARS-CoV and MERS. ${ }^{19}$ Genetic features of this novel coronavirus are compatible with the coronavirus of the same family; nevertheless its unique genetic sequences and genome that are significantly contrasting from previously genomic sequenced corona viruses (SARS$\mathrm{CoV}$ and MERS). ${ }^{20}$

Generally infectious person with SARS-CoV-2 has moderate symptoms as comparing to previous coronaviruses such as SARS and MERS related with infections point of view. Moreover, the recommended incubation period time for SARSCoV infection usually 1-7 days, while SARS-CoV-2 infection period time is bit longer, 1-14 days. ${ }^{21}$ It is quite evident that the SARSCoV-2 infected person does not accept before time diagnosis and primary health protecion, consequently, unknowingly transmit the virus through coughing or sneezing the respiratory droplets or contacting. It has already been confirmed that this COVID-19 virus is transmitted through human-to-humanthus, initially remains unnoticed and unattended. ${ }^{22}$

It is believed that bats are responsible for the origin of both SARS-CoV and MERS-CoV AND humans can easily get infected from this viruses, since directly transfer from animal dromedary camels and market civets, respectively. ${ }^{23}$

\section{TRANSMISSION OF COVID-19}

Generally COVID-19 is transmitted through respiratory droplets which are basically generated during sneezing and coughing. It also suggested to date many of the country reported this can also develop from 
asymptomatic people or patient and before outbreak of symptoms. Moreover, from toddlers to the elderly all ages is susceptible. ${ }^{24}$ Additionally, studies to date show that these droplets can escalation or transmit up to 1-2 $\mathrm{m}$ area and can deposit on any material's surface. It has been reported that COVID-19 can endure viable on any surfaces for few days but only in favourable environmental conditions but are demolished by common disinfectants like sodium hypochlorite and hydrogen peroxidein less than a minute. ${ }^{25}$ The infection form COVID-19 is acquired either by inhalation of these respiratory droplets or touching objects or surfaces contaminated by them or then touching directly the nose, eyes and mouth. It also been said that the SARS-CoV-2is also found in the faeces and contaminated water supply. It is also hypothesized that transmission of COVID-19 is through aerosolization and feco oral route. ${ }^{26}$

\section{CLINICAL FEATURES OF COVID-19}

The most noticeable clinical features of COVID-19 are fever which is not common in some people, cough, sore throat, myalgia, fatigue, headache and difficulty in breathing. Some people have described conjunctivitis. Therefore, these symptoms are indistinguishable from other respiratory diseases or infections. These symptoms are usually mild. By the end of the week infection begins gradually and the disease can grow up to or progress to pneumonia, becomes seriously ill and rapidly develops respiratory failure and death. ${ }^{27}$ Although some cases are come up with complaining about pleuirtic chest pain but majority of patients has been observed in suffers with pneumonia most of the SARS-CoV-2 infected patients. The other complications included are acute lung injury, acute kidney injury, ARDS AND shock. Furthermore, fatality rate ranged from 4 to $11 \%$ in adults in hospitalized and the fatality rate overall ages is estimated to time range between 2 and $3 \% .^{28}$ The main cardinal feature of COVID-19 is Lymphopenia. Elevated level of biochemical testing observed specifically Lactate dehydrogenase enzyme of heart or all over the body AND creatinine kinase with its different isoenzymes level in body. Half of the patients (almost 50\%) of SARS-CoV2 had abnormal (LFT) liver function, includes with increased level of amino transferase enzyme such as (ALT) alanine aminotransferase or (AST) aspartate aminotransferase. While more majority of patients had observed abnormal cardiac profile- $\mathrm{LDH}$ and $\mathrm{CK}$ with its isoenzymes and myocardial zymogram enzyme has been estimated high ranges than its normal value. ${ }^{29}$ The serum procalcitonim level on other hand determined normal, but opposite effect observed in the C-reactive protein (CRP) which was observed increased level. Similarly, the D-dimer test in some patients and approximately $1 / 3$ of patients had reported significantly high than normal. ${ }^{30}$

\section{CONCLUSION}

The scale and severity of this novel corona virus (COVID-19) outbreak has confront the health system, economic and public health framework of the China, Italy, the United states of America, Spain and other countries almost 189 countries to date $31^{\text {st }}$ March,2020. Future outbreak of Covid-2019is likely to continue. While China reported very less number of infected cases after $17^{\text {th }}$ March, 2020 as compared to previously reported and other countries. Therefore, instead to curbing this pandemic, intention should be made to plan effective comprehensive measures so that it can prevent future outbreaks as it's spreading remarkably all over the globe as compared to SARS CoV and MERS.

\section{ACKNOWLEDGEMENT}

The authors express deep thanks to Lovely Professional University, Phagwara, Punjab, 144402 (INDIA) and Galgotias University, Greater Noida, Uttar Pradesh, 201310 (INDIA).

\section{CONFLICT OF INTEREST}

The authors declare no conflict of interest.

\section{ABBREVIATIONS}

SARS-CoV-2: Severe Acute Respiratory Syndrome Coronavirus 2; MERS-CoV: Middle East respiratory syndrome; ARDS: Acute Respiratory Distres Syndrome.

\section{REFERENCES}

1. Su S, Wong G, Shi W, et al. Epidemiology, Genetic Recombination and Pathogenesis of Coronaviruses. Trends Microbiol. 2016;24(6):490-502.

2. Peiris JS, Lai ST, Poon LL, et al. Coronavirus as a possible cause of severe acute respiratory syndrome. Lancet. 2003;361(9366):1319-25.

3. Kupferschmidt K. Researchers scramble to understand camel connection to MERS. Science. 2013;341(6147):702.

4. Zhu N, Zhang D, Wang W, et al. A Novel Coronavirus from Patients with Pneumonia in China, 2019. N Engl J Med. 2020,382(8):727-33.

5. Cheng VC, Lau SK, Woo PC, Yuen KY. Severe acute respiratory syndrome coronavirus as an agent of emerging and reemerging infection. Clin Microbiol Rev. 2007;20(4):660-94.

6. Chan JF, Lau SK, To KK, Cheng VC, Woo PC, Yuen KY. Middle East respiratory syndrome coronavirus: another zoonotic betacoronavirus causing SARS-like disease. Clin Microbiol Rev. 2015;28(2):465-522.

7. Gretebeck LM, Subbarao K. Animal models for SARS and MERS coronaviruses. Curr Opin Virol. 2015;13:123-9.

8. Gralinski LE, Baric RS. Molecular pathology of emerging coronavirus infections. J Pathol. 2015;235(2):185-95. 
9. Xu Z, Shi L, Wang Y, et al. Pathological findings of COVID-19 associated with acute respiratory distress syndrome. Lancet Respir Med. 2020.

10. Taisheng LI. Diagnosis and clinical management of severe acute respiratory syndrome Coronavirus 2 (SARS-CoV-2) infection: An operational recommendation of Peking Union Medical College Hospital (V2.0). Emerging Microbes and Infections. 2020;9(1):582-5.

11. Madhugiri R, Fricke M, Marz M, Ziebuhr J. Coronavirus cis-acting RNA elements. Adv Virus Res. 2016;96:127-63.

12. Chen Y, Liu Q, Guo D. Coronaviruses: Genome structure, replication and pathogenesis. J Med Virol. 2020;92:418-23.

13. Xue WZ, et al. The 3D structure analysis of SARS-CoV S1 protein reveals a link to influenza virus neuraminidase and implications for drug and antibody discovery. Journal of Molecular Structure. 2004;681(1-3):137-41.

14. Bisht $\mathrm{H}$, et al. Severe acute respiratory syndrome coronavirus spike protein expressed by attenuated vaccinia virus protectively immunizes mice. Proc Natl Acad Sci. 2004;101(17):6641-6.

15. Rota $\mathrm{P}$, et al. Characterisation of a novel Coronavirus associated with Severe Acute Respiratory Syndrome. Science. 2003;300(5624):1394-9.

16. Tripet B, et al. Structural characterization of the SARS-Coronavirus Spike S fusion protein core. The Journal of Biological Chemistry. 2004;279(20):2083649.

17. Walls AC, Xiong X, Park YJ, Tortorici MA, Snijder J, Quispe J, et al. Unexpected Receptor Functional Mimicry Elucidates Activation of Coronavirus Fusion. Cell. 2019;176(5):1026-39.

18. Lu R, Zhao X, Li J, et al. Genomic characterisation and epidemiology of 2019 novel coronavirus: Implications for virus origins and receptor binding. Lancet. 2020;395(10224):565-74.

19. Zhou P, Yang XL, Wang XG, et al. A pneumonia outbreak associated with a new coronavirus of probable bat origin. Nature. 2020;579(7798):270-3.

20. Zumla A, Chan JF, Azhar El, Hui DS, Yuen KY. Coronaviruses: Drug discovery and therapeutic options. Nat Rev Drug Discov. 2016;15(5):327-47.
21. Zhou P, Yang XL, Wang XG, et al. Discovery of a novel coronavirus associated with the recent pneumonia outbreak in humans and its potential bat origin. Bio Rxiv. 2020. 2020.2001.2022.914952.

22. Chan JF, Yuan S, Kok KH, To KK, Chu H, Yang J, et al. A familial cluster of pneumonia associated with the 2019 novel coronavirus indicating person-toperson transmission: A study of a family cluster. Lancet. 2020;395(10223):51423.

23. Li Q, Guan X, Wu P, Wang X, Zhou L, Tong Y, et al. Early Transmission Dynamics in Wuhan, China, of Novel Coronavirus-Infected Pneumonia. N Engl J Med. 2020. Doi: 10.1056/NEJMoa2001316.

24. Rothe C, Schunk M, Sothmann P, et al. Transmission of 2019- nCoV infection from an asymptomatic contact in Germany. N Engl J Med. 2020. https://doi. org/10.1056/NEJMc2001468.

25. Kampf G, Todt D, Pfaender S, Steinmann E. Persistence of coronaviruses on inanimate surfaces and its inactivation with biocidal agents. J Hosp Infect. 2020.

26. Chen ZM, Fu JF, Shu Q, et al. Diagnosis and treatment recommendations for pediatric respiratory infection caused by the 2019 novel coronavirus. World J Pediatr. 2020;1-7. https://doi.org/10. 1007/s12519-020-00345-5.

27. Chen N, Zhou M, Dong X, et al. Epidemiological and clinical characteristics of 99 cases of 2019 novel coronavirus pneumonia in Wuhan, China: A descriptive study. Lancet. 2020;395(10223):507-13.

28. Coronavirus Outbreak. 2020. Available at: https://www.worldometers. info/ coronavirus/.

29. Wang D, Hu B, Hu C, et al. Clinical Characteristics of 138 Hospitalized Patients with 2019 Novel Coronavirus-Infected Pneumonia in Wuhan, China. JAMA. 2020.

30. Huang C, Wang Y, Li X, et al. Clinical features of patients infected with 2019 novel coronavirus in Wuhan, China. Lancet. 2020;395(10223):497-506.

Cite this article: Devi S, Singh K. Is Covid-19 Sibling of SARS AND MERS? A Review on: (Novel Covid-19). Indian $\mathrm{J}$ of Pharmaceutical Education and Research. 2020;54(3):491-5. 